\title{
A comparative study of different fluorine-containing compounds in the preparation of novel alumina binders with rich Brönsted acid sites
}

\author{
Peng Bai $\cdot$ Rui Feng $\cdot$ Songtao Liu $\cdot$ \\ Peng Zhang $\cdot$ Zifeng Yan $\cdot$ Zhengguo Tan • \\ Zhongdong Zhang $\cdot$ Xionghou Gao
}

Received: 5 June 2014/ Accepted: 8 September 2014/Published online: 7 October 2014

(c) The Author(s) 2014. This article is published with open access at Springerlink.com

\begin{abstract}
Alumina is commonly used as a catalyst binder together with aluminum sol in modern fluid catalytic cracking (FCC) catalysts. The surface acidity properties of alumina strongly affect the catalytic performance of FCC catalysts. Lewis acid sites tend to produce coke because of their dehydrogenation activity, while Brönsted ones produce less coke. Thus, it is beneficial to convert the surface Lewis acid sites into Brönsted type. Fluorine-containing modifiers have been demonstrated to be effective to generate Brönsted acid sites on alumina surface. However, different types of fluorine-containing compounds may have different modification effects. In this work, three fluorinecontaining compounds, ammonium fluoroborate $\left(\mathrm{NH}_{4} \mathrm{BF}_{4}\right)$, ammonium fluorosilicate $\left[\left(\mathrm{NH}_{4}\right)_{2} \mathrm{SiF}_{6}\right]$, and ammonium fluoride $\left(\mathrm{NH}_{4} \mathrm{~F}\right)$, were tested and compared in the modification of alumina surface acidity. Results show that $\mathrm{NH}_{4} \mathrm{BF}_{4}$ and $\left(\mathrm{NH}_{4}\right)_{2} \mathrm{SiF}_{6}$ perform equally well in the generation of Brönsted acid sites, while $\mathrm{NH}_{4} \mathrm{BF}_{4}$ is more effective in the reduction of Lewis acid sites. In comparison, $\mathrm{NH}_{4} \mathrm{~F}$ is not so effective in the generation of Brönsted acid sites as the other two compounds.
\end{abstract}

Keywords Alumina - Modification · Brönsted acid · Lewis acid · Fluorine

P. Bai $(\square) \cdot$ R. Feng $\cdot$ S. Liu $\cdot$ P. Zhang $\cdot$ Z. Yan $(\bowtie)$

State Key Laboratory of Heavy Oil Processing, PetroChina Key Laboratory of Catalysis, School of Chemical Engineering, China University of Petroleum, Qingdao 266580, China

e-mail: baipeng@upc.edu.cn

Z. Yan

e-mail: zfyancat@upc.edu.cn

Z. Tan $\cdot$ Z. Zhang $\cdot$ X. Gao

Lanzhou Petrochemical Research Center, PetroChina

Petrochemical Institute, CNPC, Lanzhou 730060, China

\section{Introduction}

Aluminum sol, an adhesive chemical, is commonly used as a binder in the fluid catalytic cracking (FCC) catalyst due to its good adhesive properties, high thermal and hydrothermal stability, excellent mechanical strength, etc. However, the conventional aluminum sol has small particle size, which causes the blockage of the pores in the catalysts. Besides, this adhesive material lacks pores in its framework and has poor pore connectivity. These features significantly deteriorate the mass and heat transfer in the FCC catalyst. Hence, in modern FCC catalysts, peptized boehmite/pseudoboehmite is usually utilized as the catalyst binder together with the aluminum sol [1-3]. In fact, the peptized pseudoboehmite usually has a highly porous structure, which provides the pores for the diffusion of hydrocarbons, facilitates the heat transfer in the catalyst particles and traps the pollutants, such as metals and coke [1].

After calcination, the alumina binder derived from the aluminum sol and peptized pseudoboehmite possesses surface acidity, which precracks the oil macromolecules into smaller ones. However, this acidity is of Lewis nature, which tends to produce coke in the cracking of hydrocarbons due to its dehydrogenation activity. In contrast, the Brönsted acid sites produce less coke [4-6]. Therefore, to reduce the coke formation, it will be advantageous to convert the Lewis acid sites into Brönsted ones. Surface modification is commonly used to realize this conversion. By doping some elements, such as halogen $[7,8]$, boron [9, 10], silicon [11, 12], sulfur [13], into the surface of alumina, Brönsted acid sites emerge and Lewis acid sites diminish.

In our previous work, fluorine-containing compounds are observed to be effective in the surface acidity 
modification of alumina. $\gamma-\mathrm{Al}_{2} \mathrm{O}_{3}$ material with rich Brönsted acid sites and lower Lewis acid sites was prepared using $\mathrm{NH}_{4} \mathrm{BF}_{4}$ as a modifier [14]. The fluorination was found to generate Brönsted acid sites and occur thorough the substitution of the hydroxyl group of six-coordinated aluminum sites. The addition of boron into the $\gamma$ $\mathrm{Al}_{2} \mathrm{O}_{3}$ structure reduced the concentration of Lewis acid sites. The observed modification result is the synergistic effect of fluorine and boron in the $\mathrm{NH}_{4} \mathrm{BF}_{4}$ modifier. The bench scale tests with heavy oil show that the modified $\gamma$ $\mathrm{Al}_{2} \mathrm{O}_{3}$ material exhibits good catalytic performance by increasing the heavy oil conversion, enhancing the gasoline and diesel yield and reducing the coke formation.

As a continuation of the previous work, in this paper, $\gamma$ $\mathrm{Al}_{2} \mathrm{O}_{3}$ materials with rich Brönsted acid sites were prepared with different fluorine-containing modifiers, such as $\mathrm{NH}_{4} \mathrm{BF}_{4}$, $\left(\mathrm{NH}_{4}\right)_{2} \mathrm{SiF}_{6}$, and $\mathrm{NH}_{4} \mathrm{~F}$. The surface modified alumina was characterized using $\mathrm{N}_{2}$ adsorption, X-ray diffraction (XRD), and Fourier transform infrared (FT-IR) spectroscopy of pyridine adsorption. The structural and surface acidity properties of alumina materials prepared using different modifiers are compared.

\section{Experimental}

\section{Materials}

Pseudoboehmite ( $\mathrm{PB}, \mathrm{Al}_{2} \mathrm{O}_{3}$ content is $71.90 \mathrm{wt} \%$ on a dry basis) was purchased from Hua Xin powder Co. Ltd. Ammonium fluoroborate $\left(\mathrm{NH}_{4} \mathrm{BF}_{4}\right.$, analytical reagent) and ammonium fluorosilicate $\left[\left(\mathrm{NH}_{4}\right)_{2} \mathrm{SiF}_{6}\right.$, analytical reagent] were purchased from Shanghai SSS Reagent Co. Ltd. Ammonium fluoride $\left(\mathrm{NH}_{4} \mathrm{~F}\right.$, analytical reagent), aqueous ammonia solution (28.0 wt $\% \mathrm{NH}_{3}$, analytical reagent), and nitric acid $\left(\mathrm{HNO}_{3}\right.$, analytical reagent) were purchased from Sinopharm Chemical Reagent Co. Ltd. All chemicals were used as received. The pristine pseudoboehmite samples calcined at different temperatures were denoted as $\mathrm{PB}-\mathrm{X}^{\circ} \mathrm{C}$ ( $\mathrm{X}$ is the calcination temperature).

\section{Preparation of modified alumina}

The preparation procedure of modified alumina is shown in Fig. 1 and described in our previous work [14]. In a typical preparation procedure, pseudoboehmite and water were vigorouly stirred to form a slurry. Then, surface modifier solution was added to the slurry, followed by the addition of peptizing agent solution $\left(1 \mathrm{M} \mathrm{HNO}_{3}\right)$. The mixture was stirred for $6 \mathrm{~h}$ at $80{ }^{\circ} \mathrm{C}$. After that, aqueous ammonia solution was dropwise added to the mixture to adjust to a $\mathrm{pH}$ of $6-10$. The obtained suspension was aged at $80{ }^{\circ} \mathrm{C}$ for $24 \mathrm{~h}$. The resulting solids were filtered, washed with

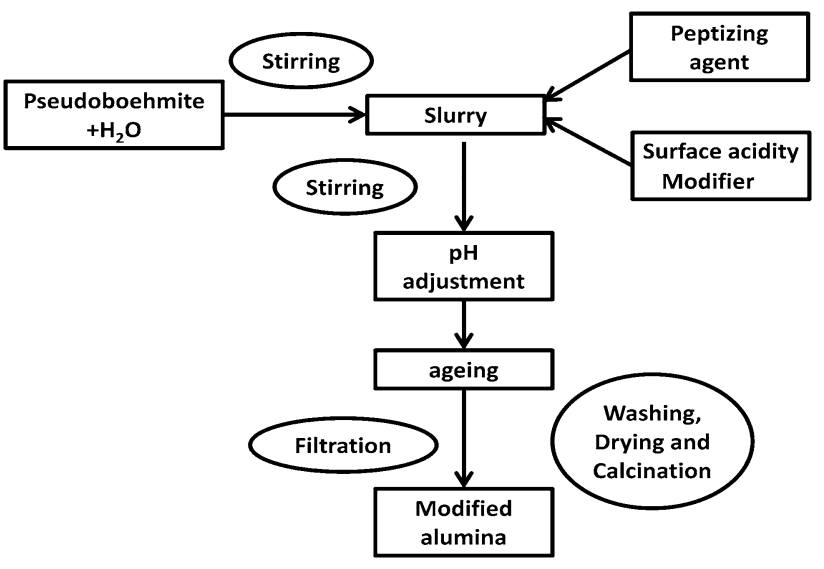

Fig. 1 Schematic diagram of the preparation procedure of modified alumina material characterization

deionized water, and dried in an electric oven for $24 \mathrm{~h}$. Finally, the dried material was calcined at $550-750{ }^{\circ} \mathrm{C}$ and a white solid was obtained. When investigating the effect of peptizing agent on the structure and acidity of alumina, no surface acidity modifier was added. While investigating the effect of surface modifiers, the peptizing agent was added as well as the modifiers. The samples prepared with $\mathrm{NH}_{4} \mathrm{BF}_{4}$ were denoted as BF- $X-Y{ }^{\circ} \mathrm{C}(X$ is the $\mathrm{F} / \mathrm{Al}$ molar ratio, varied in the range of $0-0.45$; $Y$ indicates the calcination temperature).

Nitrogen adsorption/desorption isotherms of the samples were measured on a Micromeritics TRISTAR 3000 analyzer. The samples were degassed at $573 \mathrm{~K}$ for $4 \mathrm{~h}$ prior to analysis. The specific surface areas of the samples were calculated using the Brunauer-Emmett-Teller (BET) method in the relative pressure range of $0.05-0.25$. The pore size distribution (PSD) curves were derived from the adsorption branches of the isotherms using the BarrettJoyner-Halenda (BJH) method. The pore sizes were estimated from the peak positions of the BJH PSD curves. The total pore volumes were calculated from the adsorption quantity at a relative pressure of $P / P_{0}=0.99$. The crystalline phases of the alumina samples were characterized using the XRD (Bruker Axs diffractometer, Germany) technique with a $\mathrm{Cu} \mathrm{K \alpha}$ radiation generated at $40 \mathrm{kV}$ and $40 \mathrm{~mA}$. A scanning range from 5 to $70^{\circ}$ was used with a scanning rate of $0.01 \%$. FT-IR spectra of pyridine adsorption were recorded on a Nicolet 6700 spectrometer equipped with an MCT liquid-nitrogen-cooled detector and a $\mathrm{KBr}$ beam splitter. In a typical procedure, $\gamma-\mathrm{Al}_{2} \mathrm{O}_{3}$ was ground into a fine powder and transferred into a ceramic cup. The samples were degassed at $400{ }^{\circ} \mathrm{C}$ for $2 \mathrm{~h}$ under flowing dry $\mathrm{N}_{2}(30 \mathrm{~mL} / \mathrm{min})$. The system was then cooled to $50{ }^{\circ} \mathrm{C}$ under the vacuum conditions, and sample spectra without pyridine were recorded as the background spectra. Pyridine vapor was introduced in an $\mathrm{N}_{2}$ stream online for 
about $1 \mathrm{~h}$ and then shut off. The system was equilibrated at constant temperature of $120^{\circ} \mathrm{C}$ and $<2 \times 10^{-3}$ Pa for $1 \mathrm{~h}$. The equilibration time was determined at $1 \mathrm{~h}$, because the spectra recorded did not show any change after $1 \mathrm{~h}$ of equilibration. Thereafter, the system was cooled to $50{ }^{\circ} \mathrm{C}$, and the spectra of pyridine adsorption were recorded by subtracting the background spectra without pyridine. The spectra of the samples were recorded by accumulating 64 scans at $4 \mathrm{~cm}^{-1}$ resolution. The amount of pyridine absorbed on different acid sites of the catalyst was obtained from infrared transmittance spectroscopy. The spectra at different temperatures were recorded after the system was thermally treated at the selected temperatures under vacuum for $0.5 \mathrm{~h}$ and cooled to $50{ }^{\circ} \mathrm{C}$.

\section{Results and discussion}

Properties of pseudoboehmite and effect of peptizing agent

The crystalline structures of the pseudoboehmite before and after calcination were examined using XRD and XRD patterns are shown in Fig. 2. As can be seen, the pristine pseudoboehmite exhibits mixed XRD patterns of a boehmite phase with an orthorhombic structure (JCPDS card no: 83-2384) and a bayerite crystalline phase with a monoclinic structure (JCPDS card no: 83-2256). After calcination at $550{ }^{\circ} \mathrm{C}$, both phases were converted to $\gamma$ $\mathrm{Al}_{2} \mathrm{O}_{3}$ phase, which is consistent with our previous reported results. [15] Further increasing the calcination temperature to $750{ }^{\circ} \mathrm{C}$, the $\mathrm{XRD}$ pattern obtained did not show

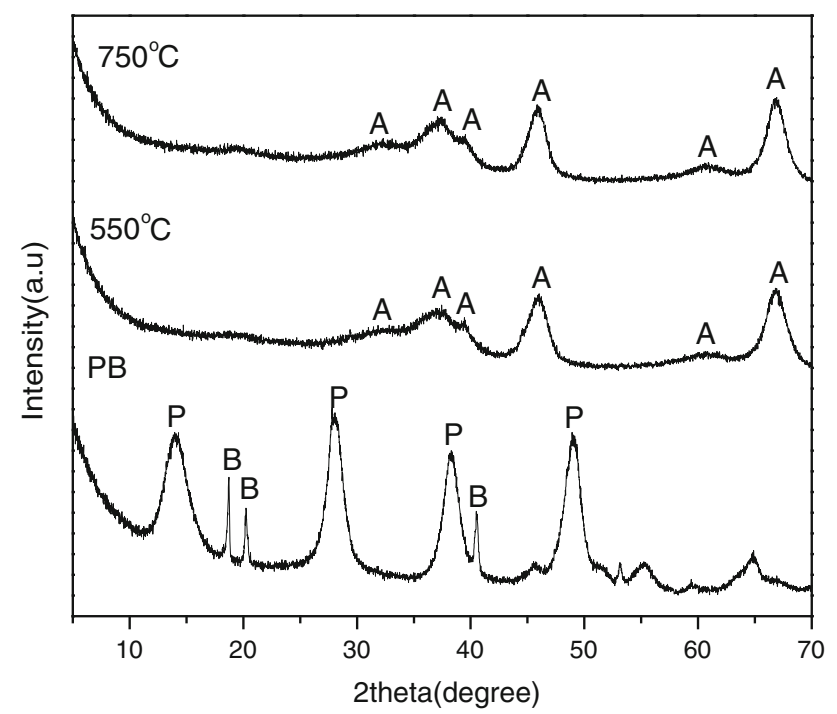

Fig. 2 XRD patterns of pseudoboehmite before and after calcination. (P, boehmite; $\mathrm{B}$, bayerite; $\mathrm{A}, \gamma-\mathrm{Al}_{2} \mathrm{O}_{3}$ ) much difference with that obtained at $550{ }^{\circ} \mathrm{C}$, which is attributed to the high thermal stability of $\gamma-\mathrm{Al}_{2} \mathrm{O}_{3}$ [16].

$\mathrm{N}_{2}$ adsorption results in Fig. 3 show that the calcined pseudoboehmite samples exhibit a type IV isotherm, indicating they are mesoporous materials. Table 1 shows that with increasing the calcination temperature from 550 to $750{ }^{\circ} \mathrm{C}$, the BET surface area of the resulting $\gamma-\mathrm{Al}_{2} \mathrm{O}_{3}$ decreases from 237.3 to $198.5 \mathrm{~m}^{2} / \mathrm{g}$, while the pore size increases from 5.7 to $6.7 \mathrm{~nm}$. Quite different from the variation of surface area and pore size, the pore volume remains almost constant at about $0.34 \mathrm{~cm}^{3} / \mathrm{g}$ with increasing the calcination temperature that may be ascribed to the enlargement of the pore size.

To characterize the surface acidity properties of the calcined pseudoboehmite sample, the resulting $\gamma-\mathrm{Al}_{2} \mathrm{O}_{3}$ samples were examined using FT-IR of pyridine adsorption technique and the spectra are shown in Fig. 4. All samples calcined at different temperatures exhibit an intense band at $1,445 \mathrm{~cm}^{-1}$ and three bands at 1,577, 1,593, and $1,613 \mathrm{~cm}^{-1}$, which are generally assigned to the Lewis acid sites [17]. With increasing the calcination temperature,

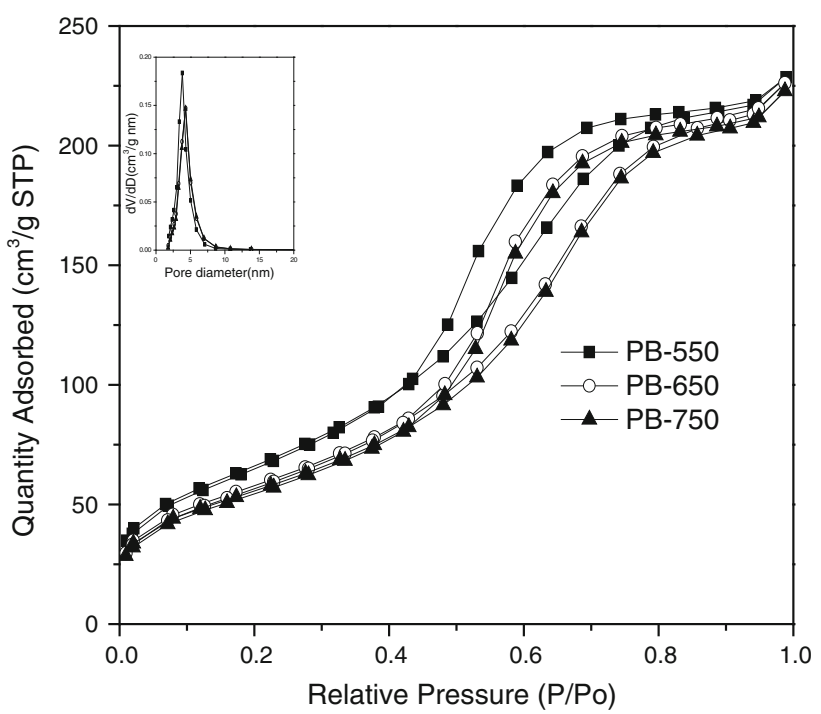

Fig. $3 \mathrm{~N}_{2}$ sorption isotherms and pore size distributions (inset) of pseudoboehmite sample after calcination at different temperatures

Table 1 Pore structure of alumina samples

\begin{tabular}{|c|c|c|c|}
\hline Samples & $\mathrm{S}_{\mathrm{BET}}\left(\mathrm{m}^{2} / \mathrm{g}\right)$ & $\mathrm{V} /\left(\mathrm{cm}^{3} / \mathrm{g}\right)$ & $\mathrm{D} /(\mathrm{nm})$ \\
\hline PB- $550{ }^{\circ} \mathrm{C}$ & 237.3 & 0.35 & 5.7 \\
\hline PB-650 ${ }^{\circ} \mathrm{C}$ & 214.6 & 0.34 & 6.5 \\
\hline PB-750 ${ }^{\circ} \mathrm{C}$ & 198.5 & 0.34 & 6.7 \\
\hline BF- $0.00-550{ }^{\circ} \mathrm{C}$ & 255.5 & 0.45 & 7.1 \\
\hline BF- $0.15-550{ }^{\circ} \mathrm{C}$ & 207.3 & 0.32 & 6.3 \\
\hline BF-0.30-550 ${ }^{\circ} \mathrm{C}$ & 233.7 & 0.41 & 7.0 \\
\hline BF- $0.45-550{ }^{\circ} \mathrm{C}$ & 200.0 & 0.36 & 10.0 \\
\hline
\end{tabular}




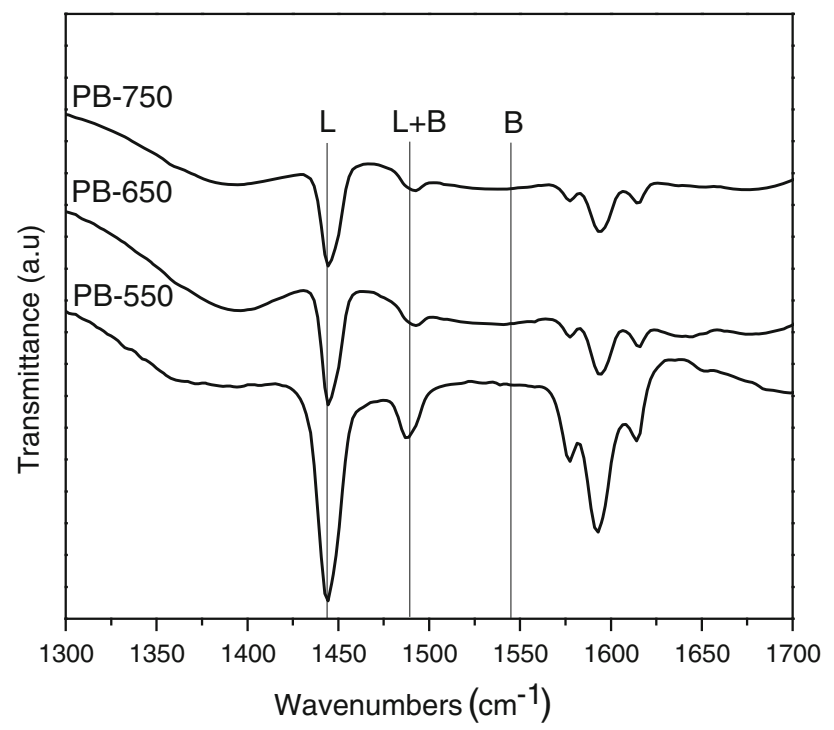

Fig. 4 FT-IR spectra of pyridine adsorption on pseudoboehmite samples calcined at different temperatures

this band intensity decreases, indicating the reduction of the concentration of Lewis acidity sites. No Brönsted acid sites with a typical IR band at ca. $1,540 \mathrm{~cm}^{-1}$ were observed [17], evidencing the absence of Brönsted acidity on the resulting $\gamma-\mathrm{Al}_{2} \mathrm{O}_{3}$ samples. The absence of Brönsted acid sites on the calcined alumina samples may be ascribed to the relatively high temperature $\left(550^{\circ} \mathrm{C}\right)$ employed for the calcination and the low thermal stability of the hydroxyls on unmodified alumina samples, which resulted in the high degree of dehydroxylation.

The calcined pseudoboehmite samples with the addition of peptizing agent $\left(\mathrm{HNO}_{3}\right)$ were also characterized using the FT-IR spectroscopy of pyridine adsorption. As shown in Fig. 5, the samples prepared with different $\mathrm{HNO}_{3} / \mathrm{Al}$ ratios exhibit sole Lewis acidity and no Brönsted acid sites were observed on these samples, verifying that the peptizing agent is not able to generate Brönsted acid sites on the alumina samples.

Surface acidity properties of alumina samples prepared with different F-containing modifiers

Fluorine-containing compounds have been demonstrated to be effective in modifying the alumina surface acidity in our previous work [14]. However, different fluorine-containing compounds were found to have different modification effect. As shown in Fig. 6, after the introduction of $\mathrm{NH}_{4} \mathrm{BF}_{4}$ with a $\mathrm{n}\left(\mathrm{F}^{-}\right) / \mathrm{n}\left(\mathrm{Al}^{3+}\right)$ ratio of 0.03 , the intensity of IR band assigned to Lewis acid sites on the alumina was dramatically reduced, while no IR band assigned to Brönsted acid sites was observed, suggesting that low concentration of $\mathrm{NH}_{4} \mathrm{BF}_{4}$ is not enough to generate IR

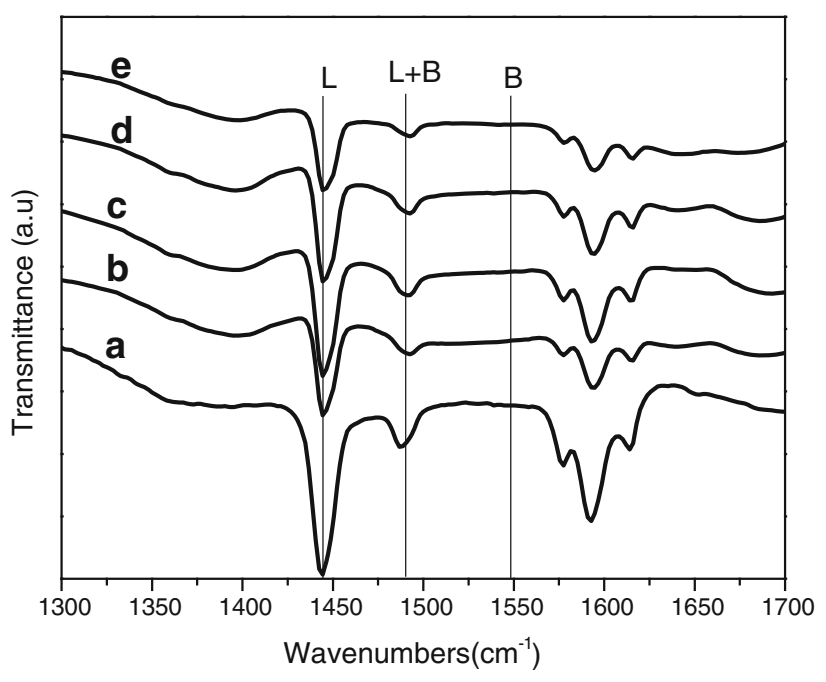

Fig. 5 FT-IR spectra of pyridine adsorption on samples prepared with different $\mathrm{n}\left(\mathrm{HNO}_{3}\right) / \mathrm{n}\left(\mathrm{Al}^{3+}\right)$ ratios after calcined at $550{ }^{\circ} \mathrm{C}$ $\left[\mathrm{n}\left(\mathrm{HNO}_{3}\right) / \mathrm{n}(\mathrm{Al}): a=0.00, b=0.03, c=0.09, d=0.15, e=0.21\right]$

discernible amount of Brönsted acid sites, but is capable of decreasing the concentration of surface Lewis acid sites. Further increasing the $\mathrm{NH}_{4} \mathrm{BF}_{4}$ doping amount to a $\mathrm{n}\left(\mathrm{F}^{-}\right)$/ $\mathrm{n}\left(\mathrm{Al}^{3+}\right)$ ratio of above 0.06 , a small IR band at ca. $1,550 \mathrm{~cm}^{-1}$ emerges, indicating the formation of Brönsted acid sites.

As shown in Fig. 7, the addition of $\left(\mathrm{NH}_{4}\right)_{2} \mathrm{SiF}_{6}$ with a low doping amount also reduced the concentration of Lewis acid sites on alumina. Similar to $\mathrm{NH}_{4} \mathrm{BF}_{4}$, when increasing the $\left(\mathrm{NH}_{4}\right)_{2} \mathrm{SiF}_{6}$ doping amount to an $\mathrm{n}\left(\mathrm{F}^{-}\right) /$ $\mathrm{n}\left(\mathrm{Al}^{3+}\right)$ ratio of above 0.06 , Brönsted acid sites formed on the alumina, indicating the addition of $\left(\mathrm{NH}_{4}\right)_{2} \mathrm{SiF}_{6}$ is also effective to induce the formation of surface Brönsted acid sites on alumina.

In contrast, the FT-IR spectra in Fig. 8 indicated that the addition of $\mathrm{NH}_{4} \mathrm{~F}$ is not so effective as $\mathrm{NH}_{4} \mathrm{BF}_{4}$ and $\left(\mathrm{NH}_{4}\right)_{2} \mathrm{SiF}_{6}$ in the generation of Brönsted acid sites on alumina. No Brönsted acid sites were observed even with an $\mathrm{n}\left(\mathrm{F}^{-}\right) / \mathrm{n}\left(\mathrm{Al}^{3+}\right)$ ratio of up to 0.09 . However, the addition of $\mathrm{NH}_{4} \mathrm{~F}$ also reduced the concentration of Lewis acid sites.

Comparison study between $\mathrm{NH}_{4} \mathrm{BF}_{4}$ and $\left(\mathrm{NH}_{4}\right)_{2} \mathrm{SiF}_{6}$ as modifiers

To compare the modification effect of $\mathrm{NH}_{4} \mathrm{BF}_{4}$ and $\left(\mathrm{NH}_{4}\right)_{2} \mathrm{SiF}_{6}$ clearly, the modified alumina samples using these two modifiers with the same $n\left(\mathrm{~F}^{-}\right) / \mathrm{n}\left(\mathrm{Al}^{3+}\right)$ ratio of 0.40 were characterized and compared under identical analysis conditions. As shown in Fig. 9, both samples exhibit a large IR band assigned to Brönsted acid sites, implying they are performing equally well in generating Brönsted acid sites on alumina. However, the reduction of Lewis acid sites using $\left(\mathrm{NH}_{4}\right)_{2} \mathrm{SiF}_{6}$ is not so pronounced as 


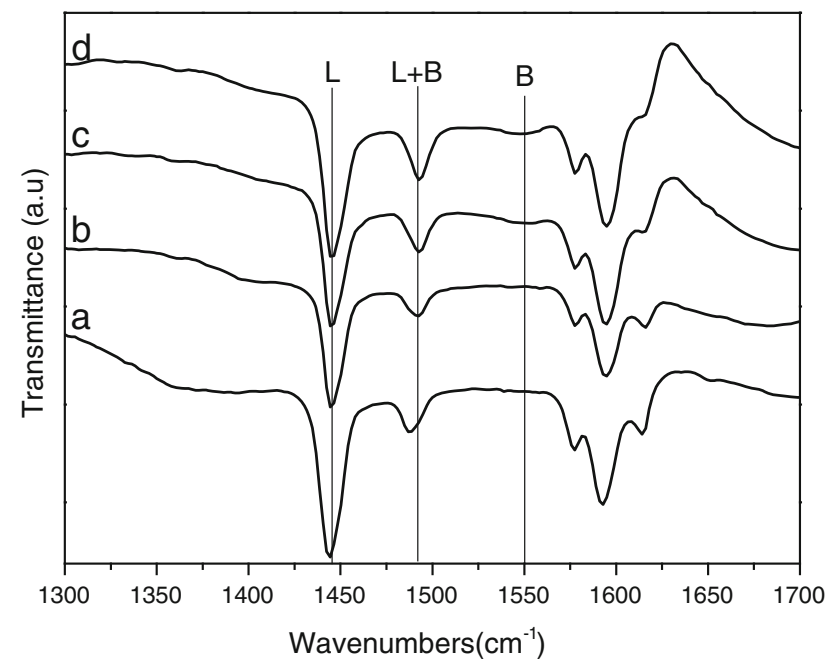

Fig. 6 FT-IR spectra of pyridine adsorption on alumina prepared with different $\mathrm{n}\left(\mathrm{NH}_{4} \mathrm{BF} 4\right) / \mathrm{n}(\mathrm{Al})$ ratios after calcined at $550{ }^{\circ} \mathrm{C}\left[\mathrm{n}\left(\mathrm{F}^{-}\right) /\right.$ $\left.\mathrm{n}\left(\mathrm{Al}^{3+}\right): a=0.00, b=0.03, c=0.06, d=0.09\right]$

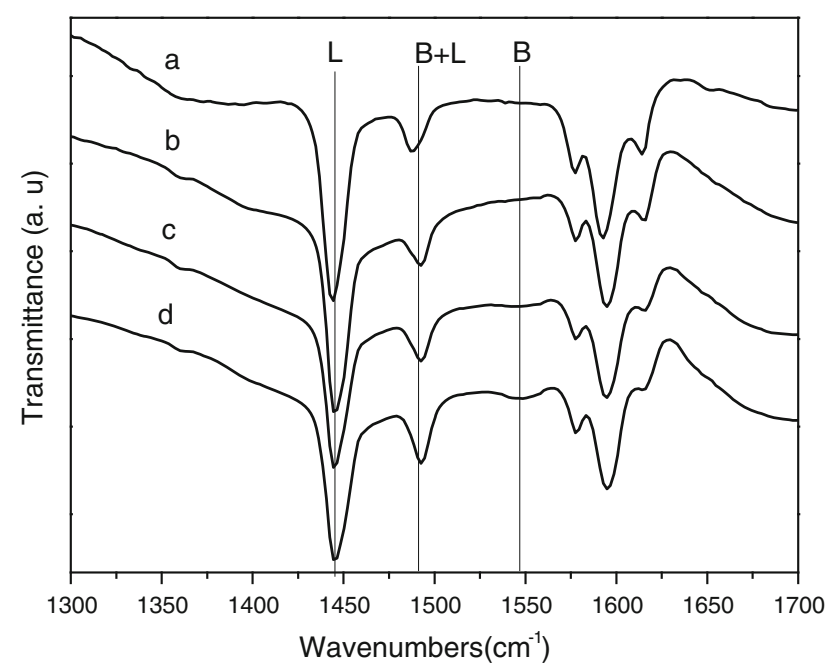

Fig. 7 FT-IR spectra of alumina prepared with different $\mathrm{n}\left(\left(\mathrm{NH}_{4}\right)_{2} \mathrm{SiF}_{6}\right) / \mathrm{n}(\mathrm{Al})$ ratios after calcined at $550{ }^{\circ} \mathrm{C}\left[\mathrm{n}\left(\mathrm{F}^{-}\right) / \mathrm{n}\left(\mathrm{Al}^{3+}\right)\right.$ : $a=0.00, b=0.03, c=0.06, d=0.09$ ]

$\mathrm{NH}_{4} \mathrm{BF}_{4}$, which may be ascribed to prominent reduction of Lewis acid sites by the insertion of boron in the structure of $\gamma-\mathrm{Al}_{2} \mathrm{O}_{3}$ as revealed by our previous study [14]. It is generally recognized that boron species are inclined to react with the positively charged $\mathrm{Al}$ atoms to give rise to the formation of $\mathrm{B}-\mathrm{O}-\mathrm{Al}$ junctions.

Based on the above experimental findings, it can be concluded that among the studied three modifiers, $\mathrm{NH}_{4} \mathrm{BF}_{4}$, $\left(\mathrm{NH}_{4}\right)_{2} \mathrm{SiF}_{6}$, and $\mathrm{NH}_{4} \mathrm{~F}, \mathrm{NH}_{4} \mathrm{BF}_{4}$ performs the best in the modification of alumina surface acidity because of the synergistic effect of F and B in the generation of Brönsted acid sites and the reduction of Lewis acid sites.

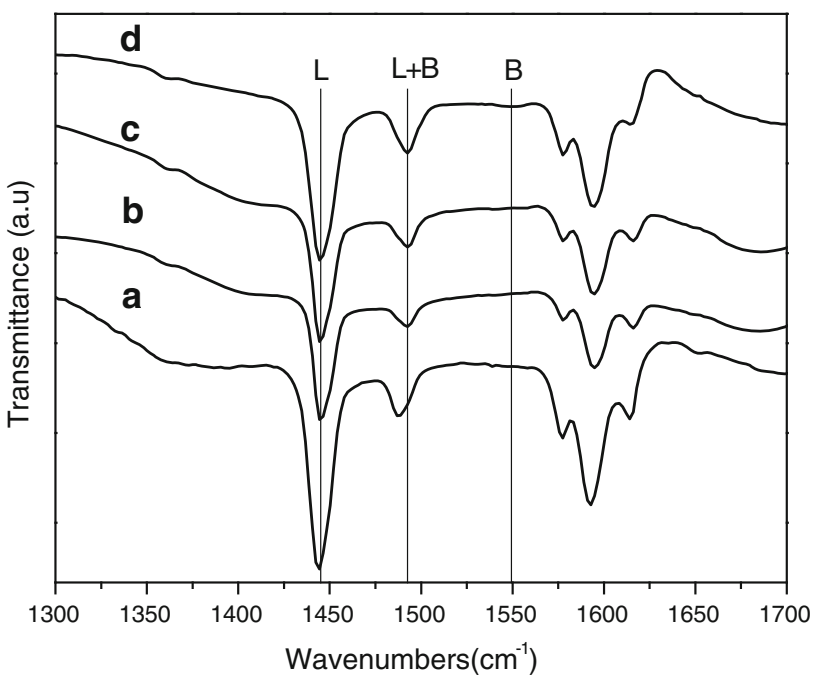

Fig. 8 FT-IR spectra of pyridine adsorption on samples prepared with different $\mathrm{n}\left(\mathrm{NH}_{4} \mathrm{~F}\right) / \mathrm{n}(\mathrm{Al})$ ratios after calcined at $550{ }^{\circ} \mathrm{C}\left[\mathrm{n}\left(\mathrm{F}^{-}\right) /\right.$ $\mathrm{n}\left(\mathrm{Al}^{3+}\right): a=0.00, b=0.03, c=0.06, d=0.09$ ]

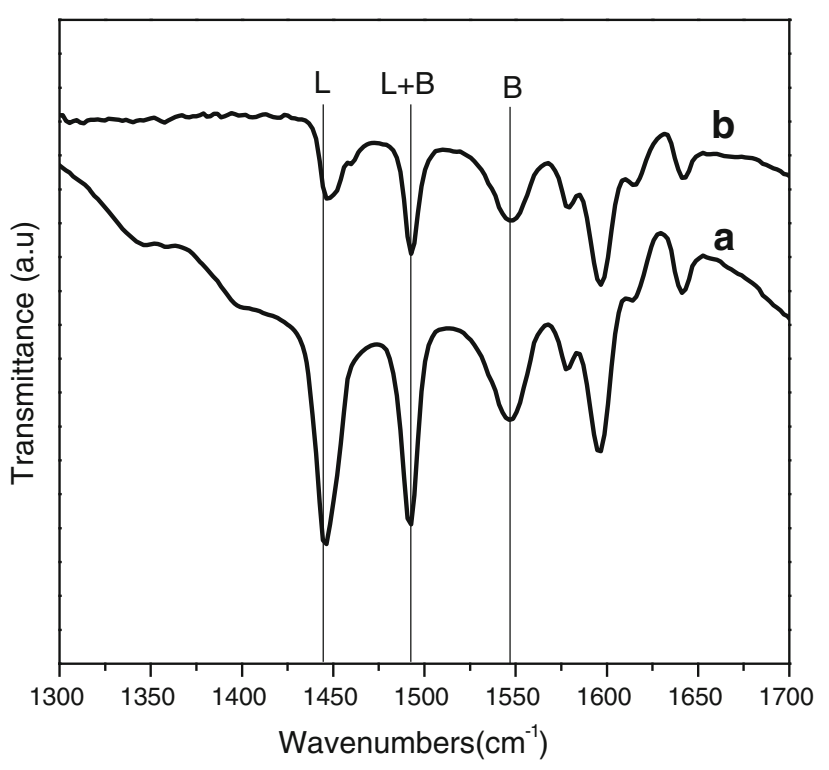

Fig. 9 FT-IR spectra of pyridine adsorption on samples prepared with different modifier after calcined at $550{ }^{\circ} \mathrm{C}\left[\mathrm{n}\left(\mathrm{F}^{-}\right) / \mathrm{n}\left(\mathrm{Al}^{3+}\right)=0.40\right]$ $\left[a,\left(\mathrm{NH}_{4}\right)_{2} \mathrm{SiF}_{6} ; b, \mathrm{NH}_{4} \mathrm{BF}_{4}\right]$

Structural and acidity properties of alumina modified using $\mathrm{NH}_{4} \mathrm{BF}_{4}$

To gain more insights into the structure properties, crystalline phase and surface acidity strength of the alumina samples modified by $\mathrm{NH}_{4} \mathrm{BF}_{4}$, the modified samples with high $\mathrm{n}\left(\mathrm{F}^{-}\right) / \mathrm{n}\left(\mathrm{Al}^{3+}\right)$ ratios were characterized using $\mathrm{N}_{2}$ adsorption, XRD, and FT-IR. As shown in Fig. 10, all the samples display a type IV isotherm, indicating the samples prepared with the addition of $\mathrm{NH}_{4} \mathrm{BF}_{4}$ even at a high 


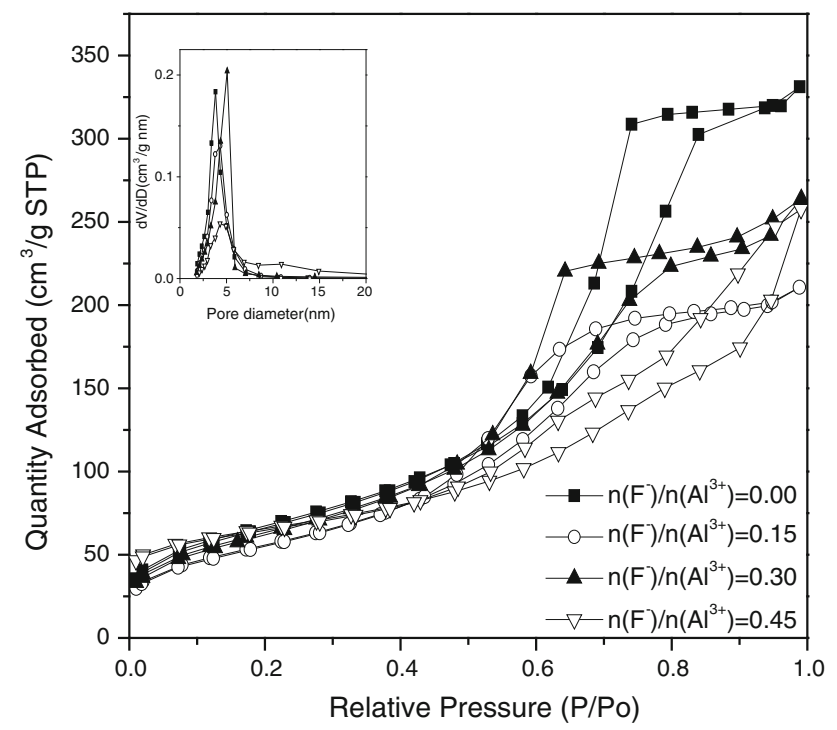

Fig. $10 \mathrm{~N}_{2}$ sorption isotherm and pore size distributions (inset) of modified alumina prepared with different $\mathrm{n}\left(\mathrm{NH}_{4} \mathrm{~F}\right) / \mathrm{n}(\mathrm{Al})$ ratios after calcined at $550{ }^{\circ} \mathrm{C}\left[\mathrm{n}\left(\mathrm{F}^{-}\right) / \mathrm{n}\left(\mathrm{Al}^{3+}\right)=0.00,0.15,0.30,0.45\right]$

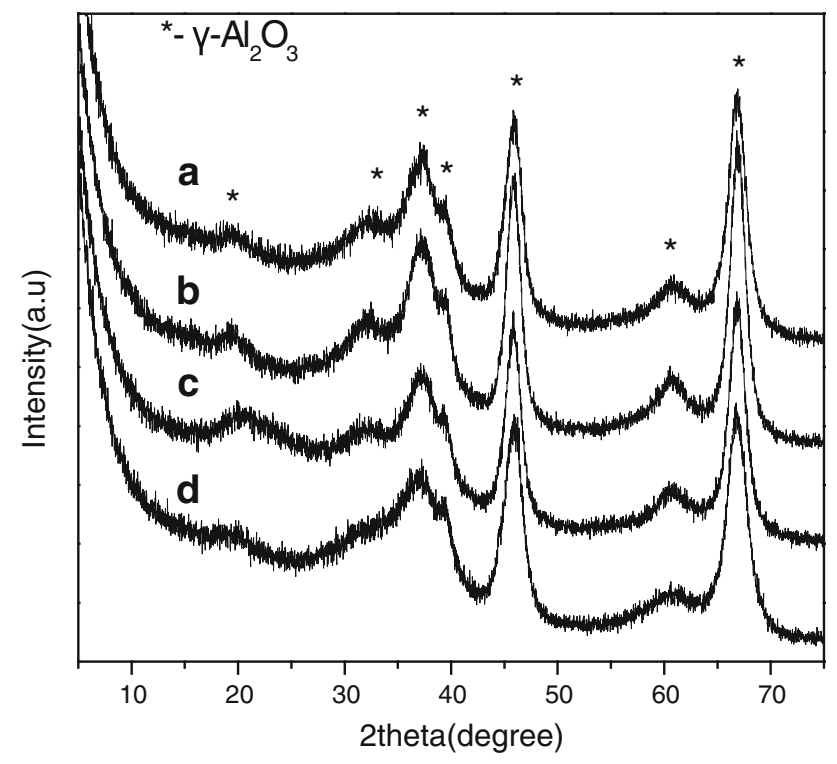

Fig. 11 XRD patterns of alumina with different $n\left(\mathrm{NH}_{4} \mathrm{~F}\right) / \mathrm{n}(\mathrm{Al})$ ratios after calcined at $550{ }^{\circ} \mathrm{C}\left[\mathrm{n}\left(\mathrm{F}^{-}\right) / \mathrm{n}\left(\mathrm{Al}^{3+}\right), \quad a=0.00, \quad b=0.15\right.$, $c=0.30, d=0.45]$

doping amount exhibit a mesoporous structure. As shown in Table 1, the BET surface area decreases from 255.5 to $200 \mathrm{~m}^{2} / \mathrm{g}$ with increasing the $\mathrm{n}\left(\mathrm{F}^{-}\right) / \mathrm{n}\left(\mathrm{Al}^{3+}\right)$ ratio from 0 to 0.45 , while the pore size increases from 7.1 to $10.0 \mathrm{~nm}$. Figure 11 shows that the samples prepared with different $\mathrm{NH}_{4} \mathrm{BF}_{4}$ doping amounts have a similar $\gamma-\mathrm{Al}_{2} \mathrm{O}_{3}$ phase without much difference, implying that the addition of $\mathrm{NH}_{4} \mathrm{BF}_{4}$ did not evidently vary the $\gamma-\mathrm{Al}_{2} \mathrm{O}_{3}$ crystalline structure of the modified alumina.

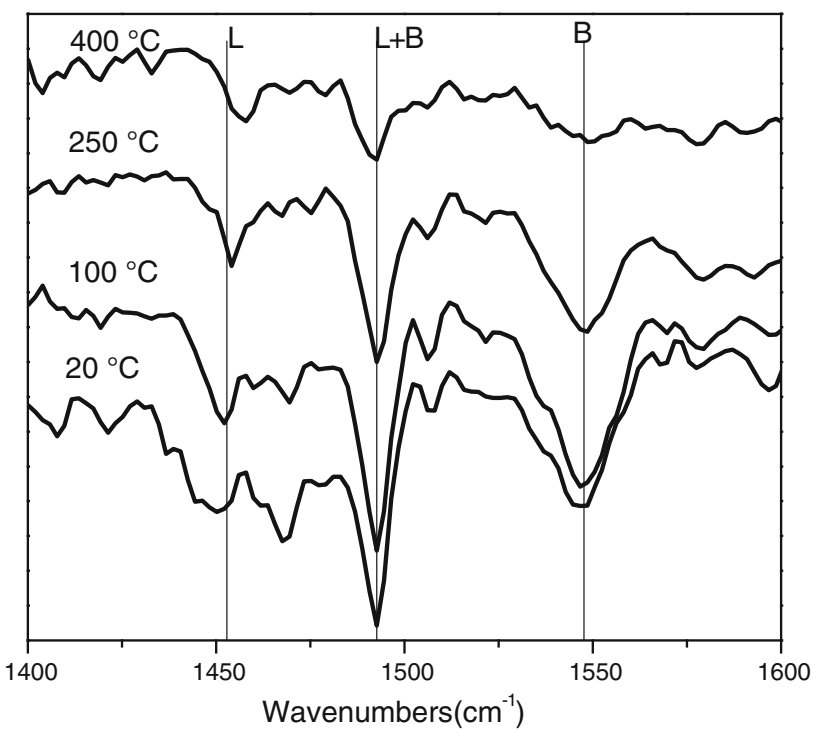

Fig. 12 FT-IR spectra of pyridine adsorption $\mathrm{NH}_{4} \mathrm{BF}_{4}$-modified alumina measured at different temperatures

The FT-IR spectra of pyridine adsorption at different temperatures are shown in Fig. 12. The spectra measured at lower temperatures exhibit strong bands at ca. 1,450 and $1,550 \mathrm{~cm}^{-1}$, demonstrating the existence of high concentration Lewis and Brönsted acid sites. With increasing the temperature, the intensity of the IR bands of both Lewis and Brönsted acid sites decreases gradually. Especially, the concentration of Brönsted acid sites reduced dramatically when the temperature increased to $400{ }^{\circ} \mathrm{C}$ and only a small amount of Brönsted acid sites were observed at that temperature. By contrast, a relatively large Lewis band still remains when heated to $400{ }^{\circ} \mathrm{C}$. These results demonstrated that on the modified alumina samples, most of the Brönsted acid sites have intermediate strength of acidity, while a large proportion of Lewis acid sites have strong strength of acidity. This finding is interesting for the optimized design of catalysts with different acidity strengths to cater for various applications.

\section{Conclusions}

Modified alumina samples with rich Brönsted acid sites were prepared using different fluorine-containing compounds as surface acidity modifiers. Among the three tested modifiers, $\mathrm{NH}_{4} \mathrm{BF}_{4},\left(\mathrm{NH}_{4}\right)_{2} \mathrm{SiF}_{6}$, and $\mathrm{NH}_{4} \mathrm{~F}, \mathrm{NH}_{4} \mathrm{BF}_{4}$ performs the best because of its effectiveness not only in generating Brönsted acid sites, but also in the reduction of the concentration of Lewis acid sites on alumina. Detailed characterization results show that the modification using $\mathrm{NH}_{4} \mathrm{BF}_{4}$ did not essentially alter the textural and crystalline structure of alumina, but changed its surface acidity. Most 
of the Brönsted acid sites of the modified alumina were found to possess intermediate strength of acidity, while a large portion of Lewis ones bear strong strength of acidity.

Acknowledgments This work was financially supported by the Joint Funds of the National Natural Science Foundation of China and China National Petroleum Corporation (U1362202), Natural Science Foundation of China (21206196), the Fundamental Research Funds for the Central Universities (14CX02050A), Shandong Provincial Natural Science Foundation (ZR2012BM014), and Funds of Development of Science and Technology of China National Petroleum Corporation (11-02-01-04, 2013A-2106).

Open Access This article is distributed under the terms of the Creative Commons Attribution License which permits any use, distribution, and reproduction in any medium, provided the original author(s) and the source are credited.

\section{References}

1. Al-Khattaf S (2003) The influence of alumina on the performance of FCC catalysts during hydrotreated VGO catalytic cracking. Energ Fuel 17:62-68

2. Scherzer J (1989) Octane-enhancing, zeolitic FCC catalysts: scientific and technical aspects. Catal Rev 31:215-354

3. Otterstedt J-E, Zhu Y-M, Sterte J (1988) Catalytic cracking of heavy oil over catalysts containing different types of zeolite $Y$ in active and inactive matrices. Appl Catal 38:143-155

4. Zholobenko V, Kustov L, Kazansky V, Loeffler E, Lohse U, Oehlmann G (1991) On the nature of the sites responsible for the enhancement of the cracking activity of HZSM-5 zeolites dealuminated under mild steaming conditions: part 2. Zeolites 11:132-134

5. Wang G, Li Z-K, Liu Y-D, Gao J-S, Xu C-M, Lan X-Y, Ning G-Q, Liang Y-M (2012) FCC-Catalyst Coking: sources and estimation of their contribution during coker gas oil cracking process. Ind Eng Chem Res 51:2247-2256

6. Qian K, Tomczak DC, Rakiewicz EF, Harding RH, Yaluris G, Cheng W-C, Zhao X, Peters AW (1997) Coke formation in the fluid catalytic cracking process by combined analytical techniques. Energ Fuel 11:596-601
7. Hughes TR, White HM, White RJ (1969) Brönsted and Lewis acid site concentrations in fluorided alumina from the infrared spectra of adsorbed pyridine species. J Catal 13:58-64

8. Muddada N, Olsbye U, Fuglerud T, Vidotto S, Marsella A, Bordiga S, Gianolio D, Leofanti G, Lamberti C (2011) The role of chlorine and additives on the density and strength of Lewis and Brønsted acidic sites of $\gamma-\mathrm{Al}_{2} \mathrm{O}_{3}$ support used in oxychlorination catalysis: a FTIR study. J Catal 284:236-246

9. Chen W, Maugé F, Van Gestel J, Nie H, Li D, Long X (2013) Effect of modification of the alumina acidity on the properties of supported Mo and CoMo sulfide catalysts. J Catal 304:47-62

10. Sato S, Kuroki M, Sodesawa T, Nozaki F, Maciel GE (1995) Surface structure and acidity of alumina-boria catalysts. J Mol Catal A Chem 104:171-177

11. Caillot M, Chaumonnot A, Digne M, Van Bokhoven JA (2014) Creation of Brønsted acidity by grafting aluminum isopropoxide on silica under controlled conditions: determination of the number of Brønsted sites and their turnover frequency for m-xylene isomerization. Chem Cat Chem 6:832-841

12. Guzmán-Castillo M, López-Salinas E, Fripiat J, Sánchez-Valente J, Hernández-Beltrán F, RodríGuez-Hernández A, NavarreteBolaños J (2003) Active sulfated alumina catalysts obtained by hydrothermal treatment. J Catal 220:317-325

13. Guzmán-Castillo M, López-Salinas E, Fripiat J, Sánchez-Valente J, Hernández-Beltrán F, RodríGuez-Hernández A, NavarreteBolaños J (2003) Active sulfated alumina catalysts obtained by hydrothermal treatment. J Catal 220:317-325

14. Feng R, Liu S, Bai P, Qiao K, Wang Y, Al-Megren HA, Rood MJ, Yan Z (2014) Preparation and characterization of $\gamma-\mathrm{Al}_{2} \mathrm{O}_{3}$ with rich Brønsted acid sites and its application in the fluid catalytic cracking process. J Phys Chem C 118:6226-6234

15. Bai P, Wu P, Yan Z, Zhao X (2009) A reverse cation-anion double hydrolysis approach to the synthesis of mesoporous $\gamma$ $\mathrm{Al}_{2} \mathrm{O}_{3}$ with a bimodal pore size distribution. Micropor Mesopor Mat 118:288-295

16. Yuan Q, Yin A-X, Luo C, Sun L-D, Zhang Y-W, Duan W-T, Liu H-C, Yan C-H (2008) Facile synthesis for ordered mesoporous $\gamma$ aluminas with high thermal stability. J Am Chem Soc 13034653472

17. Emeis C (1993) Determination of integrated molar extinction coefficients for infrared absorption bands of pyridine adsorbed on solid acid catalysts. J Catal 141:347-354 